\title{
Precision agriculture applied to soybean crop: Part II - Temporal stability of management zones
}

\author{
Eduardo Leonel Bottega ${ }^{1 *}$, Daniel Marçal de Queiroz ${ }^{2}$, Francisco de Assis de Carvalho Pinto ${ }^{2}$, \\ Domingos Sárvio Magalhães Valente ${ }^{2}$, Cristiano Márcio Alves de Souza ${ }^{3}$ \\ ${ }^{1}$ Federal University of Santa Maria, Cachoeira do Sul city, Rio Grande do Sul State, Brazil \\ ${ }^{2}$ Federal University of Viçosa, Agricultural Engineering Department, Viçosa city, Minas Gerais State, Brazil \\ ${ }^{3}$ Federal University of Grande Dourados, Faculty of Agricultural Sciences, Dourados City, Mato Grosso do Sul \\ State, Brazil
}

\section{*Corresponding author: bottega.elb@gmail.com}

\begin{abstract}
Precision farming techniques have potential applications in the Brazilian Savannah owing to the spatial variability in crop yield. The objective of this study was to evaluate the temporal stability of management zones based on the measurement of apparent soil electrical conductivity (ECa). The study was performed in a field located in the Brazilian Savannah. During the 2011/2012 crop season, ECa was measured at 160 sampling points in a 47-ha area. ECa values were then grouped into classes using the fuzzy kmeans algorithm and fertilizers were applied to the soybean crop (BMX Potencia RR) in the 2012/2013 and 2013/2014 crop seasons according to soil analysis for each class. ECa was also measured in the 2012/2013 and 2013/2014 crop seasons and the values were grouped into classes, and the maps of apparent soil electrical conductivity classes were compared using kappa coefficients. Apparent soil electrical conductivity was significant and positively correlated with each pair of crop seasons for all three seasons analyzed. The cluster analysis indicated the presence of two management zones in 2012. These management zones were adopted for fertility management in the 2012/2013 and 2013/2014 crop seasons. A comparison of the 2012 and 2013 management zone maps, based on the kappa coefficient, showed that they remained stable. The use of kappa coefficients was found to be a promising tool in the analysis of the temporal stability of management classes.
\end{abstract}

Keywords: Site-specific management, No-tillage, Soil electrical conductivity, Yield, Oxisol.

\section{Introduction}

In Brazil, precision agriculture is mainly used for managing fertilizer and lime application regimens at variable rates. These fertilizer and lime recommendations are usually defined on the basis of the analysis of soil samples obtained by grid sampling. Therefore, a large number of samples are required for precise detection of the spatial variability in soil attributes, which is a limiting factor for the use of precision agriculture (Souza et al., 2014).

The spatial and temporal variability of soil attributes can affect growth, grain development, crop quality, and final yield (Guastaferro et al., 2010). The management practices that aim to increase the profitability of agricultural production with minimal environmental impact have to be adapted to variability in field conditions, and this is the main objective of using precision agriculture techniques. However, the large number of samples required to accurately map variability also increases the cost of implementing management practices based on this variability.

Dividing the field into sub-regions called management zones that have similar factors that limit yield can help guide fertilizer input. This is a potentially important tool for managing spatial variability in crops and soils (Dalchiavon et al., 2012; Rodrigues Junior et al., 2011; Moral et al., 2011), apart from being a significant part of precision farming techniques (Xiaohu et al., 2016). For generating management zones, it is first necessary to collect information closely related to crop yield, and the variables chosen to define these management zones should be quick and inexpensive to measure. For these reasons, apparent soil electrical conductivity $(\mathrm{ECa})$ is an excellent potential variable for the delineation of management zones (Lück et al., 2009).

Numerous studies have demonstrated a correlation between soil ECa and soil chemical and physical attributes (Morari et al., 2009; Moral et al., 2010; Rodríguez-Pérez et al., 2011). The measurement of $\mathrm{ECa}$ is both fast and inexpensive compared to traditional soil sampling and laboratory analysis. Given its convenience and reliability, ECa has been used as an indirect estimator of soil variability in agricultural fields (Corwin and Lesch, 2003). The establishment of management zones based on ECa is well documented, but the information on their temporal stability is required. In this context, the objective of this study was to evaluate the temporal stability of management zones based on the mapping of apparent soil electrical conductivity.

\section{Results and Discussion}

\section{ECa variability}

The mean values for apparent soil electrical conductivity (ECa) ranged from $1.42 \mathrm{mS} \mathrm{m}^{-1}$ in 2013 to $12.24 \mathrm{mS} \mathrm{m}^{-1}$ in 2014, and from $0.82 \mathrm{mS} \mathrm{m}^{-1}$ to $19.31 \mathrm{mS} \mathrm{m}^{-1}$ for the years 
2013 and 2012. Fig. 1 shows the spatial distribution of soil moisture content $(\%)$ and soil ECa values $\left(\mathrm{mS} \mathrm{m}^{-1}\right)$ for the three study years. The lowest soil moisture content value was $12.9 \%$ in 2013 , and the highest was $29.7 \%$ in 2014 . This variation can be accounted for by the variations in soil moisture, which had a mean value of $18.48 \%$ in 2013 and $26.72 \%$ in 2014 . Soil clay and moisture content showed low coefficients of variation $(\mathrm{CV} \leq 12 \%)$, while ECa values had a moderate coefficient of variation $(12 \%<\mathrm{CV}<60 \%)$. The $\mathrm{CV}$ for soil ECa decreased during the three years of the study due to a reduction in the range between the minimum and maximum values; this observation is probably the result of soil fertility management in the study area after the establishment of management zones based on ECa measurements obtained in 2012 (Table 1).

Delineating management zones, defined as field areas that have similar factors associated with crop production, is essential for the planning and execution of actions aimed at optimizing production. As this procedure incurs significant costs, the rapid acquisition of variables used as the parameters for delineation is important, as are the low sampling costs and stability of the management zones over multiple years so that they do not require delineation for each crop season. Therefore, this study examined the stability of management zones that were delineated on the basis of apparent soil electrical conductivity (ECa) and managed differently for two consecutive crop seasons.

From 2012 to 2014, the coefficient of variation (CV) for $\mathrm{ECa}$ values measured in the experimental area decreased from 34.44 to $19.51 \%$. A possible explanation for this observation is the variation in fertilizer application rates that were based on soil characteristics for each zone. Several studies have demonstrated that ECa is affected by soil attributes associated with crop yield (Ryšan and Šařec, 2008). Moral et al. (2010) investigated the delineation of management zones based on ECa and concluded that this attribute was highly correlated with variables related to soil fertility, such as cation exchange capacity (CEC), active acidity $(\mathrm{pH})$, and total nitrogen. Thus, $\mathrm{ECa}$ is an indirect indicator of soil fertility.

\section{Correlation of ECa with soil attributes}

The results of Pearson's correlation analyses are listed in Table 2. There was a significant positive correlation among soil ECa values obtained during the three-year study period. Further, despite the wide variation in $\mathrm{ECa}$ values, the behavior of this soil attribute remained constant; i.e., areas with high ECa values in the first year consistently maintained this behavior during the next two years as did the areas with lower values. A significant correlation between soil ECa and clay content was observed only in 2013 and this observation can be justified by the low soil moisture content.

The ECa of clayey soils with low moisture content is influenced by the mineralogy thereof, which is associated with soil elasticity. Soil elasticity is the ability of the soil to expand and return to its initial state and depends on soil texture, soil moisture, and other factors, especially soil organic matter content (Braida et al., 2008). Thus, soil organic matter, in addition to its highly negative surface charge, is considered flexible and elastic with an ability to recover its original shape after removal of the load applied to it. As the study area had a soil with high levels of oxidic clay, and the organic matter content is primarily responsible for its elasticity.

Soils with low moisture exhibit a closer proximity of particles, which reduces the electrical resistivity of the soil. The ECa values for the three years were significantly correlated, regardless of the soil moisture content at the time of their measurement, with a Pearson's correlation coefficient of 0.40 between the years 2012 and 2013 and 2012 and 2014. Corwin and Lesch (2005) highlighted that $\mathrm{ECa}$ is influenced by soil moisture content such that wetter areas tend to have higher ECa values. The ability of soil to retain water is also closely related to the texture and the amount of organic matter in the soil.

Although soil attributes affect ECa readings, the pattern of spatial distribution of $\mathrm{ECa}$, rather than its magnitude, is important in delineating management zones. King et al. (2005) have shown that the spatial distribution patterns of ECa values remain stable even when the amplitude of the measured values changes.

The ECa was significantly correlated with the clay content only for the year 2013, and the soil average moisture content $(18.08 \%)$ was low at the time of ECa measurement for that year. This result can be explained by how the soil conducts electricity. According to Corwin and Lesch (2005), soil conducts electricity in three ways: (1) via the liquid phase, through the amount of water and dissolved solids in this phase that are present in the macropores of the soil, (2) via the solid-liquid phase, depending on the concentration of exchangeable cations associated with clay minerals, and (3) via the solid phase, based on the proximity between soil particles.

During the three-year study period, the soil ECa values displayed spatial dependence, and the coefficients of determination $\left(\mathrm{R}^{2}\right)$ for the models that fit the data were greater than 0.95 . The range of the ECa semivariograma values decreased from the first year to the third year and their residual sum of squares was relatively low. The fit of the semivariogram models was determined to be an accurate estimation, and even though the $\mathrm{R}^{2}$ for ECa_2012 was low, the regression coefficient (ideally equal to one) and the intercept (ideally equal to zero) showed satisfactory values (Table 3).

Fig. 1 illustrates that the spatial behavior of the soil moisture content remained unchanged in the study area, regardless of the year studied and that it varied only in the magnitude of the values. With respect to soil ECa values, the spatial behavior was not consistent and only certain trends in spatial distribution were retained. However, the thematic maps of spatial variability in soil ECa for the years 2012 and 2014 were more similar with each other.

Studies conducted by Besson et al. (2010) observed that spatial and temporal variability in soil electrical resistivity has a strong relationship with the spatial and temporal variability in soil water content. According to these authors, the sites with greater water content have lower electrical resistivity and vice versa. However, such a relationship was not observed in the present study. Nonetheless, this behavior can be explained by the fact that ECa values are influenced by a combination of soil salts, mineralogy of the clay, and temperature of the soil (Brevik et al., 2006).

Fig. 2 shows the graphs for Fuzziness Performance Index (FPI) and Modified Partition Entropy (MPE), according to the number of zones of cluster analysis for the study period.

\section{ECa management zone stability}

The optimal number of management zones are obtained when the following parameters are minimized (Song et al., 2009). For the years 2012 (A) and 2014 (B), the optimal number of classes was determined to be two zones while that for 2013 (C) was four. This may have been due to the relatively lower soil moisture content in 2012 and 2014. Further, the average 
Table 1. Descriptive statistics of the clay content, apparent electrical conductivity and moisture content for the three study years.

\begin{tabular}{|c|c|c|c|c|c|c|c|c|c|}
\hline Attributes & $\mathbf{N}^{(1)}$ & Mean & Median & Minimum & Maximum & $\mathrm{s}^{(2)}$ & $\mathrm{CV}(\%)^{(3)}$ & $\mathrm{Cs}^{(4)}$ & $\mathrm{Ck}^{(5)}$ \\
\hline $\mathrm{CC}^{(6)}$ & 80 & 68.45 & 70.06 & 36.38 & 87.06 & 7.39 & 10.80 & -1.25 & 3.09 \\
\hline ECa_2012 ${ }^{(7)}$ & 160 & 6.19 & 5.94 & 2.74 & 19.31 & 2.13 & 34.44 & 2.24 & 9.29 \\
\hline MC_2012 $2^{(8)}$ & 160 & 24.46 & 24.99 & 15.75 & 28.02 & 2.23 & 9.14 & -1.88 & 3.89 \\
\hline ECa_2013 & 160 & 1.42 & 1.36 & 0.82 & 3.02 & 0.40 & 27.92 & 1.10 & 1.99 \\
\hline MC_2013 & 160 & 18.48 & 18.86 & 12.90 & 20.06 & 1.58 & 8.53 & -2.28 & 4.66 \\
\hline ECa_2014 & 160 & 12.24 & 11.77 & 7.93 & 17.79 & 2.39 & 19.51 & 0.51 & -0.75 \\
\hline MC_2014 & 160 & 26.72 & 27.00 & 21.45 & 29.70 & 1.64 & 6.15 & -0.82 & 0.42 \\
\hline
\end{tabular}

${ }^{1}$ Number of samples; ${ }^{2}$ Standard Deviation; ${ }^{3}$ Coefficient of Variation; ${ }^{4}$ Skewness coefficient; ${ }^{5}$ Kurtosis coefficient; ${ }^{6}$ Clay content in the soil (dag kg $\left.{ }^{-1}\right) ;{ }^{7}$ Apparent soil electrical conductivity in $2012\left(\mathrm{mS} \mathrm{m}^{-1}\right) ;{ }^{8}$ Soil moisture in $2012(\%)$.

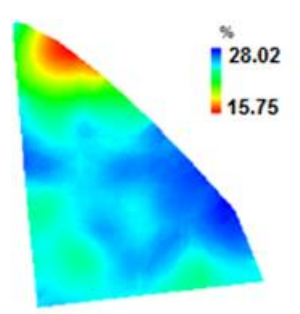

A

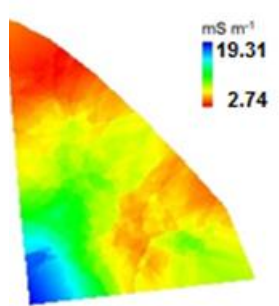

A

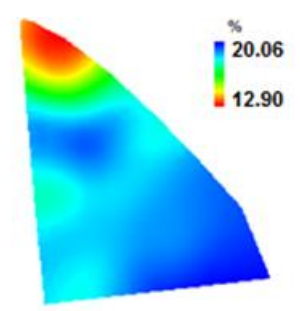

B

Soil Moisture Content

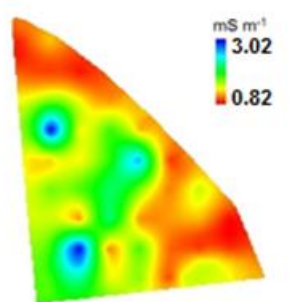

B

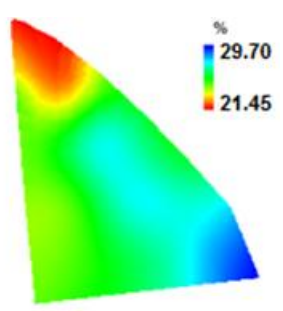

C

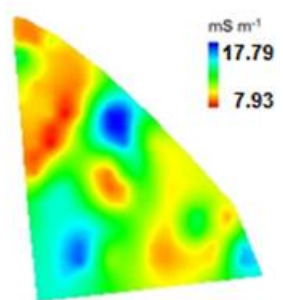

C

Apparent soil electrical conductivity

Fig 1. Thematic maps of spatial variability of the moisture content and apparent electrical conductivity of the soil for the three study years: 2012 (A); 2013 (B) and $2014(\mathrm{C})$.

Table 2. Pearson's correlation analysis between the clay content and apparent electrical conductivity of the soil for the three study years.

\begin{tabular}{|c|c|c|c|c|}
\hline Attributes & $\mathrm{CC}$ & ECa_12 & ECa_13 & ECa_14 \\
\hline $\mathrm{CC}^{(1)}$ & 1.00 & & & \\
\hline ECa_2012 & 0.08 & 1.00 & & \\
\hline ECa_2013 & $0.16^{*}$ & $0.40 *$ & 1.00 & \\
\hline ECa_2014 & 0.10 & $0.40 *$ & $0.30 *$ & 1.00 \\
\hline
\end{tabular}
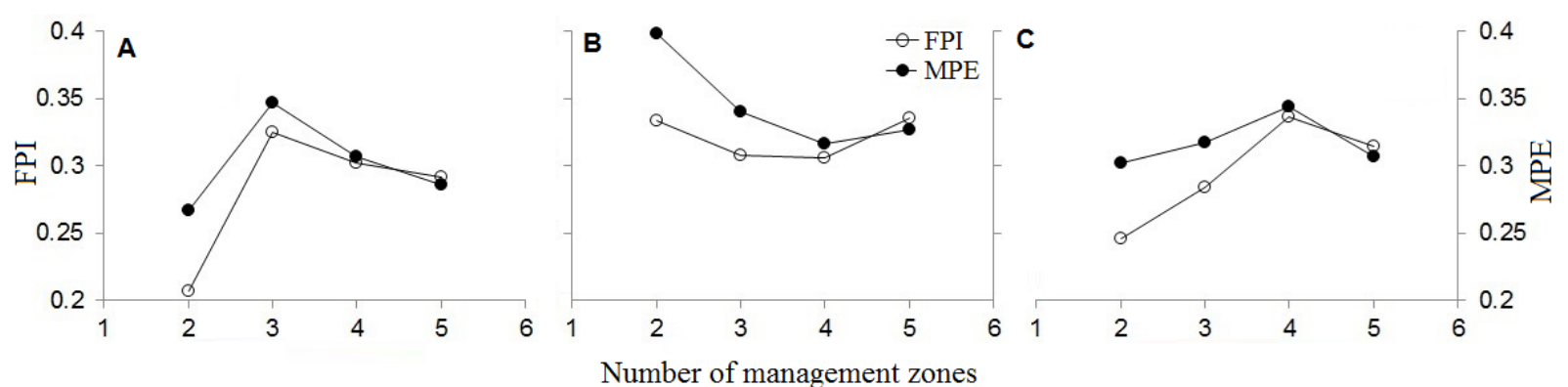

Fig 2. Values for the Fuzzy Performance Index (FPI) and for Modified Partition Entropy (MPE) according to the different number of management zones based on the apparent soil electrical conductivity for the three study years: 2012 (A); 2013 (B) and 2014 (C). 
Table 3. Parameters of theoretical semivariograms and cross-validation analysis for modeling the spatial dependence of the apparent soil electrical conductivity for the three study years.

\begin{tabular}{|c|c|c|c|c|c|c|}
\hline \multirow{2}{*}{ Attributes } & \multicolumn{6}{|c|}{ Geostatistical parameters } \\
\hline & Model & $a^{(1)}$ & $\mathrm{C}_{0}+\mathrm{C}^{(2)}$ & $\mathrm{C}_{0}^{(3)}$ & $\operatorname{RSS}^{(5)}$ & $\mathrm{R}^{2(6)}$ \\
\hline $\mathrm{ECa} \_2012^{(7)}$ & Gaussian & 539 & 5.79 & 2.33 & 0.08 & 0.99 \\
\hline ECa_2013 & Exponential & 167 & 0.19 & 0.02 & $6.3 \mathrm{E}-04$ & 0.96 \\
\hline \multirow[t]{3}{*}{ ECa_2014 } & Exponential & 166 & 7.03 & 0.01 & 1.38 & 0.98 \\
\hline & \multicolumn{6}{|c|}{ Cross-validation parameters } \\
\hline & Regression C & & $\mathrm{Y}^{(8)}$ & & $\mathrm{EPP}^{(9)}$ & $\mathrm{R}^{2}$ \\
\hline ECa_2012 & 1.02 & & -0.14 & & 1.57 & 0.29 \\
\hline ECa_2013 & 1.17 & & -0.25 & & 0.18 & 0.80 \\
\hline $\mathrm{ECa} 2014$ & 1.09 & & -1.10 & & 0.68 & 0.92 \\
\hline
\end{tabular}
conductivity in $2012\left(\mathrm{mS} \mathrm{m}^{-1}\right) ;{ }^{8}$ Intercept; ${ }^{9}$ Standard error of prediction.

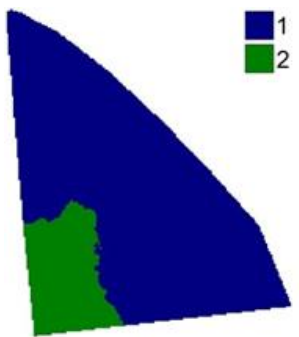

A

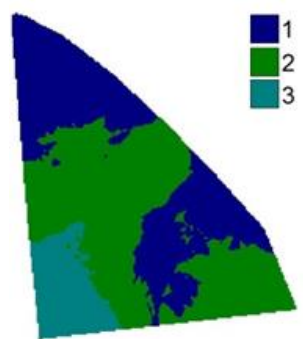

A

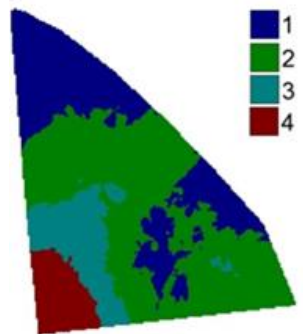

A

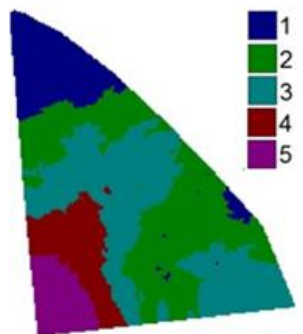

A

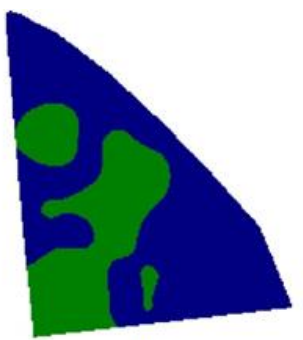

B

two management zones

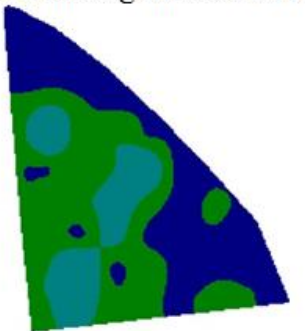

B

three management zones

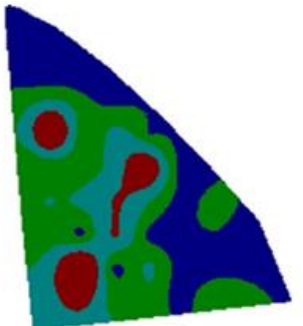

B

four management zones

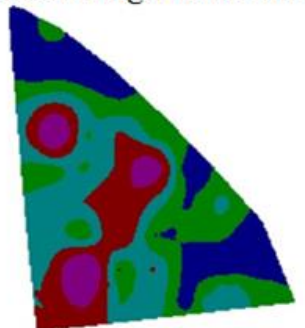

B

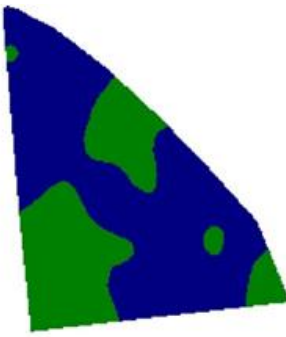

C

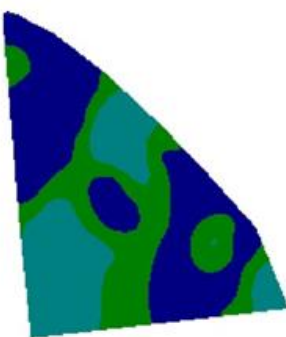

$\mathrm{C}$

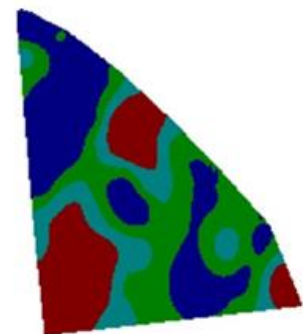

C

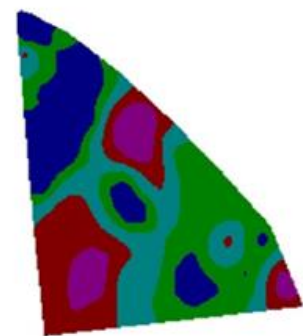

$\mathrm{C}$

five management zones

Fig 3. Management zones delimited on the basis of the spatial variability of the apparent electrical conductivity of the soil for the studied agricultural years 2012 (A); 2013 (B) and 2014 (C). 
Table 4. Kappa coefficients between the management zone maps for the three study years.

\begin{tabular}{lcccc}
\hline \multirow{2}{*}{ Years } & \multicolumn{4}{c}{ Number of management zones } \\
\cline { 2 - 5 } & 2 & 3 & 4 & 5 \\
\hline $2012 \times 2013$ & $0.33^{\mathrm{b}}$ & $0.29^{\mathrm{b}}$ & $0.22^{\mathrm{a}}$ & $0.22^{\mathrm{a}}$ \\
$2013 \times 2014$ & $0.33^{\mathrm{b}}$ & $0.24^{\mathrm{b}}$ & $0.18^{\mathrm{b}}$ & $0.17^{\mathrm{b}}$ \\
$2012 \times 2014$ & $0.52^{\mathrm{a}}$ & $0.36^{\mathrm{a}}$ & $0.26^{\mathrm{a}}$ & $0.25^{\mathrm{a}}$ \\
\hline Values followed by the same letter in the column indiate equl kappa coefficiet
\end{tabular}

Values followed by the same letter in the column indicate equal kappa coefficient values between management zones based on a $\mathrm{Z}$ test at $5 \%$ level.

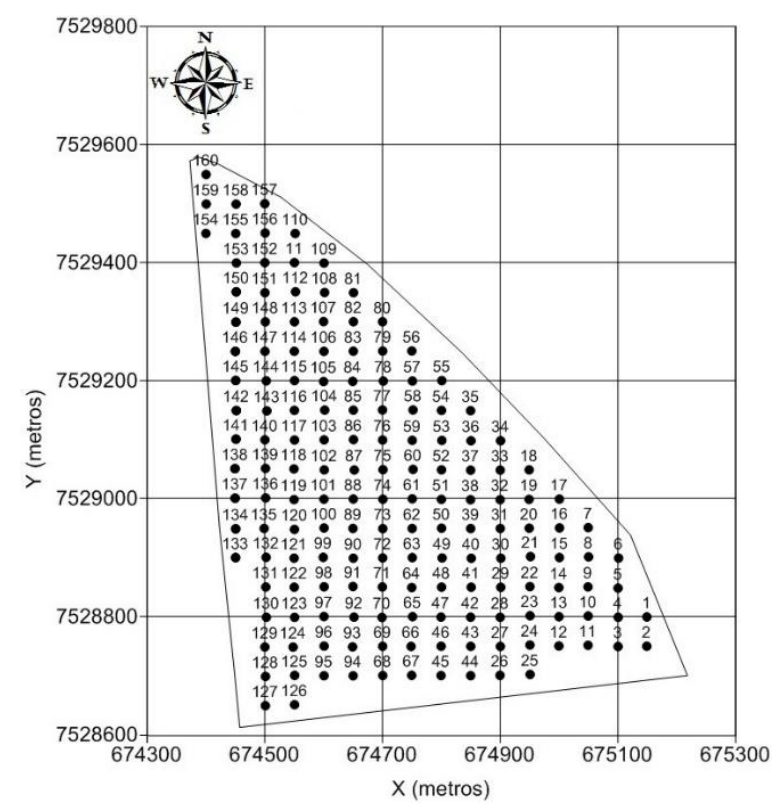

Fig 4. Representative map of the study area and of the 160 sampling points used as a reference for data collection. UTM Coordinates, Zone 21 South, datum SIRGAS2000.

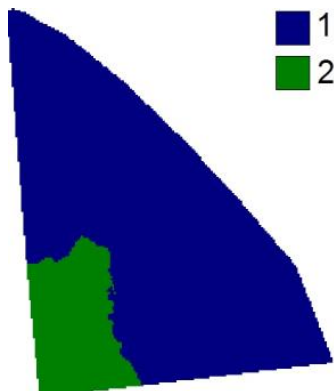

Fig 5. Delineation of two management zones (1 and 2) suggested by the zone map generated using soil ECa data.

moisture content for 2012 and 2014 was similar leading to similarities in FPI and MPE. In 2013 and 2014, the study area was already being managed according to zones established in 2012. Even though it appears that the water content did not affect the spatial distribution pattern of soil ECa, the change in the optimal number of management zones from four in 2013 to two in the other two years may be associated with the variation in soil water content at the time the ECa was determined. In 2013, the soil water content was lower than in the other two years, and this may have affected how other soil attributes determine soil ECa. In fact, Corwin and Lesch (2003) recommend that ECa can be measured only when soil is near its field capacity because as water content becomes more homogeneous, the ECa approaches the electrical conductivity of the soil aqueous extract, and any variation in the ECa could be linked to dissolved solutes and soil physical attributes. Michot et al. (2003) noted that greater the concentration of exchangeable cations in the soil solution, greater is their ability to conduct electricity and, consequently, greater the correlation between $\mathrm{ECa}$ and soil fertility. Fig. 3 shows the management zones generated on the basis of apparent soil electrical conductivity for the three study years: 2012 (A), 2013 (B) and 2014 (C). The maps generated for 2012 and 2014, regardless of the number of zones, are more similar than when either is compared with those for the year 2013. It is important to highlight here that the map adopted for soil fertility management in the study area consisted of two zones, and had been generated from soil ECa mapping in 2012. Over the study period, the southwest portion of the field remained class 2 (green), and the variations only occurred in the other regions of the field. As there is no method to quantify the stability of management zones, in this study, kappa coefficient for the management zone maps generated for the different years was calculated (Table 4). This coefficient was used as a parameter for stability analysis because kappa coefficient (ranging from 0 to 1 ) increases with increasing similarity between the maps. 
The highest kappa coefficient value of 0.52 was obtained for the zone maps generated for 2012 and 2014. This coefficient is indicative of a good classification. Higher kappa coefficients were observed for the zone maps generated in 2012 and 2014 regardless of the number of zones adapted; this can be explained by the similar temporal variations in soil moisture content at the time of ECa measurement. In addition, an increase in the number of zones, independent of the study year, tended to reduce the kappa value, implying a reduction in map similarity.

Contrary to the above, the map of the zones established for fertility management can be considered as being stable over the three years because, based on the calculated kappa coefficients, the maps were reasonably similar with a coefficient of 0.33 . Poor classifications were observed in the maps with 4 and 5 zones for the years 2013 and 2014. As stated previously, variations in the soil moisture content at the time of the ECa measurements may have caused this behavior.

In this study, kappa coefficient was found to be a potential tool for studying the temporal stability of the management zones, predominantly owing to its utility in establishing similarity between ECa maps. The greatest coefficient obtained, 0.52 , was between the maps that represented two management zones and were generated in 2012 and 2014, demonstrating that management zones generated in 2012 tended to persist until the year 2014. This result is as expected given the similarity in soil moisture contents at the time of ECa measurement in these two years. However, kappa coefficient tended to decrease, indicating a greater difference between the management zones, as the number of delineated management zones increased.

\section{Materials and Methods}

\section{Study area description}

This study was performed on a farm located in the municipality of Ponta Porã, Mato Grosso do Sul, Brazil (22 $32^{\prime} 09^{\prime \prime}$ South latitude and $55^{\circ} 43^{\prime} 33^{\prime \prime}$ 'West longitude). The farm has 450 ha of land under agriculture where soybean (Glycine max) and corn (Zea mays) have been cultivated in a crop succession system using no-tillage for more than 12 years. The predominant soil type is a clayey Oxisol (EMBRAPA, 2006). The present study was performed in a 47-ha portion of the field.

\section{Experimental procedure}

The sample collection for laboratory assessment of soil attributes was performed using a systematic sampling grid with 160 points spaced 50 meter apart. The apparent soil electrical conductivity (ECa) was also determined at these points for three consecutive years, namely, 2012, 2013, and 2014.

In the first year, the soil was sampled at 80 points as a composite soil sample formed from five simple samples taken randomly at a distance of no more than five meters from a sampling point and at a soil depth of 0.00 to 0.20 meters. Such sampling was performed to determine, in particular, the soil clay content of the study area. A soil sample was also collected at every point of ECa measurement to determine soil moisture content. Fig. 4 illustrates the sampling grid and the study area. A Garmin GNSS receiver (Global Navigation Satellite System), GPSMAP 62, was used to locate sampling points within the study area.
Texture analysis was performed using the pipette method. The thermogravimetric method was used (Ruiz, 2005). Apparent soil electrical conductivity was quantified using the electrical resistivity method. In this method, four equally spaced electrodes were introduced into the ground in the Wenner Matrix arrangement (Corwin and Lesh, 2003), using a portable conductivity meter, the Landviser ${ }^{\circledR}$ LandMapper ${ }^{\circledR}$ ERM-02. The spacing between the electrodes was $0.20 \mathrm{~m}$. Electric current was applied to the external electrodes, and the potential difference was measured in the internal electrodes (Corwin and Hedrickx, 2002; Corwin and Lesh, 2003).

\section{Statistical analysis}

The data from soil texture analysis, ECa, and soil moisture results were subjected to descriptive statistical analysis, including mean, median, minimum, maximum, and standard deviation, coefficient of variation, and skewness and kurtosis coefficients to characterize its distribution. Pearson's' correlation coefficient was calculated among clay content, moisture content, and ECa soil measurements for the three crop seasons studied. Descriptive statistics and the correlation coefficients were calculated using the Statistica 7.0 software. Next, geostatistical methods were used to analyze the spatial dependence of soil attributes by fitting variograms, assuming stationarity of the intrinsic hypothesis

(Equation

1). $\hat{y}(h)=\frac{1}{2 N(h)} \sum_{i=1}^{N(h)}\left[Z\left(x_{i}\right)-Z\left(x_{i+h}\right)\right]^{2}$

where

$\hat{\gamma}(h)=$ Semivariance as a function of the distance (h) between pairs of points;

$\mathrm{h}=$ Distance between pairs of points, $\mathrm{m}$;

$\mathrm{N}(\mathrm{h})=$ Number of experimental pairs of observations $\mathrm{Z}\left(\mathrm{x}_{\mathrm{i}}\right)$ and $\mathrm{Z}\left(\mathrm{x}_{\mathrm{i}+\mathrm{h}}\right)$ separated by a distance $\mathrm{h}$.

The following variogram models were tested, namely, the linear model with sill, Gaussian, spherical, and exponential models. The model that resulted in the smallest residual sum of squares (RSS) was chosen to represent the theoretical variogram. The following parameters were determined during the analysis: nugget effect $\left(\mathrm{C}_{0}\right)$, sill $\left(\mathrm{C}_{0}+\mathrm{C}\right)$, and range $(\mathrm{A})$. Once a spatial dependence was detected, a thematic map of the soil attribute was generated. Map interpolation was performed using ordinary kriging. For estimating the values at non-sampled locations, 16 of the closest neighbors were used such that the neighborhood radius was equal to the range value found when fitting the variogram. Subsequently, management zone maps (with 2, 3, 4, and 5 classes) were generated based on measured ECa values for each of the three crop seasons.

Kappa coefficient was used to evaluate the temporal stability of management zones, as there is no established method. Kappa coefficient was calculated to evaluate the similarity between the maps using a hypothesis test that compared a reference map (management zones generated in 2012) with other subsequently generated maps (management zone maps for 2013 and 2014).

For the first estimate, the lack of agreement between the maps was calculated to produce error matrices that were then used for calculating the kappa coefficient between management zone maps generated in the three-year study period. The value of kappa coefficient determines the similarity between a reference map and other maps. Kappa values equal to zero imply that the maps are different and the 
similarity between the maps is said to increase as the kappa coefficient approaches one.

When kappa coefficient is equal to one, the maps are identical. Kappa coefficient was calculated according to a method proposed by Hudson and Ramm (1987) and subjected to a Z-test at $5 \%$ level, as described by Congalton and Mead (1983). In this study, the classifications with kappa coefficient $\geq 0.50$ were considered stable.

Calculations of spatial variability in clay content, ECa, and moisture, the delineation of management zones, and the calculation of kappa statistics were performed using KrigMe, developed by Valente (2010). This software uses the fuzzy kmeans classification algorithm for cluster analysis and the generation of management classes. The number of management classes that best represent the data group was defined as a function of the Fuzziness Performance Index (FPI), which estimates the degree of separation of members into different classes, and the Modified Partition Entropy (MPE), which estimates the degree of disorganization created by the number of classes. These indices have values between 0 and 1 , and the optimal number of management zones is obtained when both indices are minimized (Song et al., 2009). These indices were calculated for grouping the data into 2, 3, 4, or 5 classes. Fig. 5 shows the management zone map delineated in 2012 and used for the management of soil fertility for the 2012/2013 and 2013/2014 crop seasons.

\section{Conclusion}

Apparent soil electrical conductivity was significantly and positively correlated during the study period. The map containing two management zones generated in 2012 and used for fertility management in the 2012/2013 and 2013/2014 crop season remained stable, as determined by the kappa coefficient. The use of kappa coefficients proved to be a promising tool for the analysis of the temporal stability of specifically defined management zones.

\section{Acknowledgements}

The authors thank the National Council for Scientific and Technological Development (CNPq) and the Research Foundation of the State of Minas Gerais (FAPEMIG) for the scholarships and financial support to this study and the São Judas Tadeu Farm for offering the study area and logistics required in this work.

\section{References}

Besson A, Cousin I, Bourennane H, Nicoullaud B, Pasquier C, Richard G, Dorigny A, King D (2010) The spatial and temporal organization of soil water at the field scale as described by electrical resistivity measurements. Eur J Soil Sci. 61:120-132.

Braida JA, Reichert JM, Reinert DJ, Sequinatto L (2008) Elasticidade do solo em função da umidade e do teor de carbono orgânico. Rev Bras Cienc Solo. 32(2):477-485.

Brevik E, Fenton T, Lazari A (2006) Soil electrical conductivity as a function of soil water content and implications for soil mapping. Precis Agric. 7(6):393-404.

Congalton RG, Mead RA (1983) A quantitative method to test for consistency and correctness in photointerpretation. Photogramm Eng Rem S. 49(1):69-74.

Corwin DL, Hendrickx JMH (2002) Electrical Resistivity: Wenner Array. In: SILVA JS Methods of Soil Analysis: Part 4 - Physical Methods, Madison, Wisconsin, USA: SSSA Book Series.

Corwin DL, Lesch SM (2003) Application of Soil Electrical Conductivity to Precision Agriculture: Theory, Principles, and Guidelines. Agron J. 95(3):471-471.
Corwin DL, Lesch SM (2005) Apparent soil electrical conductivity measurements in agriculture. Comput Electron Agr. 46(1-3):1143.

Dalchiavon FC, Carvalho MP, Andreotti M, Montanari R (2012) Variabilidade espacial de atributos da fertilidade de um Latossolo Vermelho Distroférrico sob Sistema Plantio Direto. Rev Cienc Agron. 43(3):453-461.

EMBRAPA (Empresa Brasileira de Pesquisa Agropecuária) (2006) Sistema brasileiro de classificação de solos, 2nd edn. Rio de Janeiro: EMBRAPA-SPI, 306 p.

Guastaferro F, Castrignano A, De Benedetto D, Sollitto D, Troccoli A, Cafarelli B (2010) A comparison of different algorithms for the delineation of management zones. Precis Agric. 11(6):600-620.

Hudson WD, Ramm CW (1987) Correct formulation of the kappa coefficient agreement. Photogramm Eng Rem S. 53:421-422.

King J, Dampney P, Lark R, Wheeler H, Bradley R, Mayr T (2005) Mapping potential crop management zones within fields: use of yield-map series and patterns of soil physical properties identified by electromagnetic induction sensing. Precis Agric. 6(2):167-181.

Lück E, Gebbers R, Ruehlmann J, Spangenberg U (2009) Electrical conductivity mapping for precision farming. Near Surf Geophys. $7: 15-25$.

Michot D, Benderitter Y, Dorigny A, Nicoullaud B, King D, Tabbagh A (2003) Spatial and temporal monitoring of soil water content with an irrigated corn crop cover using surface electrical resistivity tomography. Water Resour Res. 39(5):1138.

Moral FJ, Terrón JM, Silva JRM (2010) Delineation of management zones using mobile measurements of soil apparent electrical conductivity and multivariate geostatistical techniques. Soil Till Res. 106(2):335-343.

Moral FJ, Terrón JM, Rebollo FJ (2011) Site-specific management zones based on the Rasch model and geostatistical techniques. Comput Electron Agr. 75:223-230.

Morari F, Castrignanò A, Pagliarin C (2009) Application of multivariate geostatistics in delineating management zones within a gravelly vineyard using geo-electrical sensors. Comp Electron Agr. 68:97-107.

Rodrigues Junior FA, Vieira LB, Queiroz DM, Santos NT (2011) Geração de zonas de manejo para cafeicultura empregando-se sensor SPAD e análise foliar. Rev Bras Eng Agric Amb. 15(8):778-787.

Rodríguez-Pérez JR, Plant RE, Lambert JJ, Smart DR (2011) Using apparent soil electrical conductivity (ECa) to characterize vineyard soils of high clay content. Precis Agric. 12(6):775-794.

Ruiz HA (2005) Incremento da exatidão da análise granulométrica do solo por meio da coleta da suspensão (silte + argila). Rev Bras Cienc Solo. 29:297-300.

Ryšan L, Šařec O (2008) Research of correlation between electric soil conductivity and yield based on the use of GPS technology. Res Agr Eng. 54(3):136-147.

Song X, Wang J, Huang W, Liu L, Yan G, Pu R (2009) The delineation of agricultural management zones with high resolution remotely sensed data. Precis Agric. 10(6):471-487.

Souza ZM, Souza GS, Marques Júnior J, Pereira GT (2014) Número de amostras na análise geoestatística e na krigagem de mapas de atributos do solo. Cienc Rural. 44(2):261-268.

Valente DSM (2010) Desenvolvimento de um sistema de apoio à decisão para definir zonas de manejo em cafeicultura de precisão. Tese (Doutorado em Engenharia Agrícola) - Departamento de Engenharia Agrícola, Universidade Federal de Viçosa, Viçosa, $122 \mathrm{p}$.

Zhang X, Jiang L, Qiu X, Qiu J, Juan Wang, Zhu Y (2016) An improved method of delineating rectangular management zones using a semivariogram-based technique. Comput Electron Agri. 121:74-83. 